\title{
ANALISIS TINGKAT KESEHATAN BANK UMUM BUMN KONVENSIONAL DAN BANK
} UMUM BUMN SYARIAH

\author{
Amelia Rahmi \\ Universitas Pakuan, Bogor \\ Email: amelia.rahmi@unpak.ac.id
}

\section{KETERANGAN ARTIKEL}

Riwayat Artikel

Diterima: 10 Mei 2019

Direvisi: 1 Juni 2019

Disetujui: 31 Juni 2019

Klasifikasi JEL

G20, G30

Keywords: RGEC (Risk Profile, Good Corporate Governance, Earnings and Capital), Conventional Banks and Islamic Banks

Kata kunci: Analisis RGEC (Risk Profile, Good Corporate Governance, Earnings and Capital), Bank Konvensional dan Bank Syariah

\section{ABSTRACT}

The purpose of this study is to determine the soundness of sharia BUMN Bank and conventional BUMN bank if measured by RGEC method in 2014-2018. This research is a comparative study that is a study that is comparing, the variable is the same as the independent variable, but for samples that are more than one, or in a time frame different. The population of this study is the Conventional BUMN Bank and Islamic BUMN Bank with period observations between 2014 and 2018. While the sample in this study taken by using a purposive sampling technique. The results showed that the risk of conventional commercial bank loans with Islamic commercial banks there are differences. That commercial bank GCG conventional with Islamic commercial banks there are differences. That conventional commercial bank earnings with Islamic banks there are differences. That conventional commercial bank capital with banks general sharia there are differences. This means that the soundness of conventional commercial banks and banks general sharia based on RGEC there are differences.

\section{ABSTRAK}

Tujuan dari penelitian adalah mengetahui tingkat kesehatan Bank BUMN Syariah dan Bank BUMN Konvensional jika diukur menggunakan pendekatan RGEC (Risk Profile, Good Corporate Governance, Earnings, Capital) pada tahun 2014-2018. Penelitian ini termasuk penelitian komparatif yaitu suatu penelitian yang bersifat membandingkan, variabel sama dengan variabel mandiri, tetapi untuk sampel yang lebih dari satu, atau dalam waktu yang berbeda. Populasi penelitian ini Bank BUMN Konvensional dan Bank BUMN Syariah dengan periode pengamatan antara tahun 2014 sampai dengan tahun 2018 . Sedangkan sampel dalam penelitian ini diambil dengan menggunakan teknik purposive sampling. Hasil penelitian menunjukkan bahwa risiko kredit bank umum konvensional dengan bank umum syariah terdapat perbedaan. Bahwa GCG bank umum konvensional dengan bank umum syariah terdapat perbedaan. Bahwa earnings bank umum konvensional dengan bank umum syariah terdapat perbedaan. Bahwa capital bank umum konvensional dengan bank umum syariah terdapat perbedaan. Artinya tingkat kesehatan bank umum konvensional dengan bank umum syariah berdasarkan RGEC terdapat perbedaan.

\section{PENDAHULUAN}

Bank adalah lembaga keuangan yang kegiatan operasional bergantung pada dana yang dipercayakan oleh pengguna jasanya atau nasabah. Kestabilan suatu perekonomian negara juga dipengaruhi oleh kesehatan sistem 
Amelia Rahmi: Analisis Tingkat Kesehatan ...

perbankannya. Tanpa adanya lembaga bank yang bisa menghimpun, mengelola dan menyalurkan dana dari rakyat, sektor-sektor perekonomian tidak akan berkembang. Oleh karena itu, sangatlah penting jika manajemen operasional dan prinsip kerjanya dikembangkan dengan baik dan sistematis.

Bank sebagai lembaga yang menjadi perantara pihak penabung dan peminjam, memiliki risiko yang sangat besar. Risiko tersebut bisa bermacam-macam. Mulai dari Risiko pasar, Risiko kredit macet, likuiditas, reputasi, hukum, operasional dan lain sebagainya.

Berawal dari risiko-risiko inilah sebuah perbankan harus benar-benar dipantau agar dapat berjalan sebagaimana mestinya. Disinilah peran dari Bank Indonesia sebagai induk dari segala perbankan untuk melakukan evaluasi dan penilaian lewat prosedur RGEC.

Oleh karena itu tingkat kesehatan bank menjadi hal yang penting untuk diperhatikan, hal tersebut didukung dengan adanya Penilaian Tingkat Kesehatan Bank Umum yang dikeluarkan oleh Bank Indonesia pada PBI No. 13/1/PBI/2011. Penilaian tingkat kesehatan bank umum dimaksudkan agar bank mampu untuk melakukan kegiatan operasionalnya secara normal dan dapat memenuhi semua kewajibannya dengan baik. Berdasarkan PBI No. 13 tahun 2011 Pasal 6, faktor penilaian kesehatan bank yang wajib dipenuhi oleh bank meliputi Risk Profile, Good Corporate Governance, Earnings, dan Capital yang biasanya disebut sebagai metode RGEC. Metode RGEC menggantikan metode penilaian kesehatan bank umum yang menggunakan metode CAMELS.

Faktor Profil Risiko (Risk Profile) dilakukan penilaian melalui risiko inheren dan kualitas penerapan manajemen risiko dalam operasional bank yang terdiri dari delapan risiko antara lain risiko kredit, risiko pasar, risiko likuiditas, risiko hukum, risiko operasional, risiko stratejik, risiko kepatuhan dan risiko reputasi.
Penilaian terhadap faktor GCG (Good Corporate Governance) merupakan penilaian terhadap manajemen bank atas pelaksanaan prinsip-prinsip GCG. Pelaksanaan prinsipprinsip tersebut harus sesuai dengan peraturan yang telah ditetapkan demi tercapainya good corporate governance yang mendukung tercapainya tujuan perusahaan. Indikator penilaian GCG yaitu menggunakan bobot penilaian berdasarkan Governance Structure, Governance Processes, dan Governance Outcome.

Penilaian terhadap faktor Rentabilitas (Earnings) meliputi penilaian terhadap kemampuan bank dalam menciptakan laba dengan menggunakan rasio Return on Assets (ROA) dan Net Interest Margin (NIM).

Penilaian terhadap faktor Permodalan (Capital) meliputi penilaian terhadap tingkat kecukupan permodalan dan pengelolaan permodalan (PBI No. 13/1/PBI/2011).

Bagi perbankan, hasil akhir penilaian kondisi bank tersebut dapat digunakan sebagai salah satu sarana dalam menetapkan strategi usaha di waktu yang akan datang sedangkan bagi Bank Indonesia dapat digunakan sebagai sarana penetapan dan implementasi strategi pengawasan bank oleh Bank Indonesia.

Adapun tujuan dari penelitian adalah mengetahui tingkat kesehatan Bank BUMN Syariah dan Bank BUMN Konvensional jika diukur menggunakan pendekatan RGEC (Risk Profile, Good Corporate Governance, Earnings, Capital) pada tahun 2014-2018.

\section{KAJIAN LITERATUR Bank}

Bank merupakan lembaga keuangan dengan kegiatan operasional menghimpun dana dari masyarakat dan menyalurkan dana kepada masyarakat serta memberikan jasa bank lainnya (Kasmir, 2015).

Perbankan di Indonesia terbagi menjadi dua, yaitu perbankan konvensional dan perbankan berlandaskan prinsip islam yaitu perbankan syariah (Anggraini dkk, 2015)

Metode RGEC 
Kinerja bank dapat mencerminkan tingkat kesehatan bank. Kinerja bank yang semakin baik, maka tingkat kesehatan bank juga semakin baik juga dan sebaliknya jika kinerja bank menurun, akan menyebabkan tingkat kesehatan bank juga menurun (Rahman, dkk., 2016)

Peraturan Bank Indonesia No. 13/1/PBI/2011 tentang penilaian tingkat kesehatan bank umum, RGEC memiliki 4 kriteria penilaian, yaitu risk profile (profil risiko), good corporate governance (GCG), earning (rentabilitas) dan capital (modal).

\section{Risk Profile (Profil Risiko)}

Dalam dunia bisnis, risiko (risk) didefinisikan sebagai kemungkinan akan adanya kerugian di masa mendatang. Perbankan dikatakan sehat jika ia mampu meminimalkan risiko-risiko yang ada dalam dunia perbankan.

Risiko yang dihadapi perbankan dalam dunia finansial bisa berupa risiko kredit macet, risiko likuditas (kemampuan membayar utang jangka pendek), Risiko reputasi, hukum, dan lain sebagainya. Semakin mampu perbankan meminimalisasi risiko tersebut maka perbankan tersebut akan semakin sehat.

Oleh karena itu tingkat kesehatan bank menjadi hal yang penting untuk diperhatikan, hal tersebut didukung dengan adanya Penilaian Tingkat Kesehatan Bank Umum yang dikeluarkan oleh Bank Indonesia pada PBI No.13/1/PBI/2011.

Penilaian tingkat kesehatan bank umum dimaksudkan agar bank mampu untuk melakukan kegiatan operasionalnya secara normal dan dapat memenuhi semua kewajibannya dengan baik. Berdasarkan PBI No. 13 tahun 2011 Pasal 6, faktor penilaian kesehatan bank yang wajib dipenuhi oleh bank meliputi Risk Profile, Good Corporate Governance, Earnings, dan Capital yang biasanya disebut sebagai metode RGEC.

Metode RGEC menggantikan metode penilaian kesehatan bank umum yang menggunakan metode CAMELS. Metode CAMELS (Capital, Assets Quality, Management, Earning, Liquidity and Sensitivity) mulai digunakan pada tahun 2004 juga diterbitkan oleh Bank Indonesia dan merupakan penyempurnaan dari metode sebelumnya yaitu CAMEL (Capital, Assets Quality, Management, Earning and Liquidity). Penilaian Kesehatan Bank menurut metode RGEC dibagi menjadi 4 faktor yang wajib dipenuhi oleh bank, yaitu meliputi Risk Profile, Good Corporate Governance, Earnings, dan Capital.

Faktor Profil Risiko (Risk Profile) dilakukan penilaian melalui risiko inheren dan kualitas penerapan manajemen risiko dalam operasional bank yang terdiri dari delapan risiko antara lain risiko kredit, risiko pasar, risiko likuiditas, risiko hukum, risiko operasional, risiko stratejik, risiko kepatuhan dan risiko reputasi.

Penilaian terhadap faktor GCG (Good Corporate Governance) merupakan penilaian terhadap manajemen bank atas pelaksanaan prinsipprinsip GCG. Pelaksanaan prinsip-prinsip tersebut harus sesuai dengan peraturan yang telah ditetapkan demi tercapainya good corporate governance yang mendukung tercapainya tujuan perusahaan. Indikator penilaian GCG yaitu menggunakan bobot penilaian berdasarkan Governance Structure, Governance Processes, dan Governance Outcome.

Penilaian terhadap faktor Rentabilitas (Earnings) meliputi penilaian terhadap kemampuan bank dalam menciptakan laba dengan menggunakan rasio Return on Assets (ROA) dan Net Interest Margin (NIM). Penilaian terhadap faktor Permodalan (Capital) meliputi penilaian terhadap tingkat kecukupan permodalan dan pengelolaan permodalan ( $\mathrm{PBI}$ No.13/1/PBI/2011).

\section{Good Corporate Governance}

Konsep GCG di abad ke-21 seakan menjadi prasyarat utama untuk menjaga 
eksistensi agar tidak bangkrut. Bukan hanya perbankan, namun setiap korporasi harus menjunjung tinggi nilai-nilai GCG untuk mewujudkan dan membangun sistem bisnis yang kokoh. GCG yang baik akan menghasilkan hubungan baik dan berkelanjutan antara pihak internal dan pihak luar (pemegang saham, investor, dan masyarakat).

Dengan demikian, jika bank gagal mengimplementasikan konsep GCG maka berarti ia "sakit" di mata Bank Indonesia maupun di mata nasabah dan pihak lainnya yang berkepentingan. Beberapa indikator dalam GCG yang harus diterapkan oleh bank adalah transparansi, akuntabilitas, fairness (keadilan), responsibilitas, dan independensi.

Penerapan GCG pada bank umum dilaksanakan berdasarkan Surat Edaran Bank Indonesia nomor 15/15/DPNP/2013 bertujuan untuk menjalankan kepatuhan terhadap peraturan perundangundangan yang berlaku serta melindungi kepentingan stakeholders. Bank diwajibkan melaksanakan penilaian sendiri (self assessment) GCG terhadap 11 aspek penilaian yang ditentukan oleh Bank Indonesia. Hasil penilaian sendiri (self assessment) GCG bank harus dipublikasikan (Tessa, 2016)

\section{Earning}

Bank dikatakan sehat atau tidak, dilihat dari earning (kinerja keuangan dalam menghasilkan laba). Dalam hal ini Bank Indonesia sebagai pemegang otoritas tertinggi untuk menilai, menggunakan pendekatan rasio ROA (Return on Asset). ROA yaitu konsep untuk melihat seberapa besar modal yang dimiliki perbankan dalam menghasilkan laba setelah pajak. Jika bank memiliki modal yang cukup besar, namun laba yang dihasilkan sangatlah kecil (di bawah batas kewajaran), maka bank tersebut patut dicurigai oleh Bank Indonesia (BI).

\section{Capital}

Kemudian, yang menjadi indikator untuk menentukan apakah bank tersebut sehat atau tidak adalah dengan melihat tingkat kecukupan modal (Capital Adequacy Ratio - CAR). CAR akan ditetapkan lebih rendah atau lebih tinggi oleh $\mathrm{BI}$ tergantung pada Risk Profile masingmasing perbankan, karena setiap bank memiliki tingkat risiko yang berbeda. Sederhananya bank yang dinilai sangat berisiko tentunya pengawas $\mathrm{BI}$ akan meminta kebutuhan minimum modalnya (CAR) lebih besar.

Jika modal yang disediakan bank kecil sedangkan profile risk bank tersebut tinggi, maka tentu saja bank tersebut akan mendapatkan pengawasan khusus dari $\mathrm{BI}$ sebab memungkinkan untuk dimasukan dalam kategori tidak sehat.

\section{METODE PENELITIAN}

Penelitian ini menggunakan jenis penelitian explanatory survey karena bertujuan untuk menguji hipotesis, yang umumnya merupakan penelitian yang menjelaskan fenomena dalam bentuk hubungan antar variabel. Penelitian ini memiliki tingkatan yang lebih tinggi bila dibandingkan dengan penelitian deskriptif dan komparatif. Penelitian ini menggunakan statistik inferensial, yaitu statistik yang digunakan untuk menganalisis data sampel dan hasilnya tersebut dapat diberlakukan untuk populasi. Penelitian ini juga termasuk penelitian komparatif yaitu suatu penelitian yang bersifat membandingkan, variabel sama dengan variabel mandiri, tetapi untuk sampel yang lebih dari satu, atau dalam waktu yang berbeda (Siregar, 2010).

Populasi penelitian ini Bank BUMN Syariah dan Bank BUMN Konvensional dengan periode pengamatan antara tahun 2014 sampai dengan tahun 2018. Sedangkan sampel dalam penelitian ini diambil dengan menggunakan teknik purposive sampling, suatu teknik penentuan sampel dengan pertimbangan tertentu, yaitu (Sugiyono, 2012): Pertama, Bank Umum Konvensional dan Bank Syariah yang terdaftar di Bank Indonesia dan mulai beroperasi sebelum tahun 2014. Kedua, Bank Umum Konvensional dan Bank Syariah yang termasuk dalam kategori lima besar 
berdasarkan asset. Ketiga, Bank Umum Konvensional dan Bank Syariah yang merupakan Badan Usaha Milik Negara (BUMN). Keempat, Bank Umum Konvensional dan Bank Syariah BUMN yang mempublikasikan atau memiliki laporan keuangan tahun 2014-2018.

Berdasarkan kriteria di atas maka didapatkan tiga bank BUMN konvensional dan bank Syariah, yaitu: Bank konvensional antara lain: PT Bank BRI, PT Bank Mandiri, dan PT Bank BNI. Sedangkan bank Syariah antara lain: PT Bank BRI Syariah, PT Bank Syariah Mandiri, dan PT Bank BNI Syariah.

Jenis data yang digunakan dalam penelitian ini adalah data sekunder yaitu berasal dari laporan tahunan yang dipublikasikan oleh ketiga bank konvensional dan bank Syariah tersebut. Data yang digunakan berupa data kuantitatif berupa laporan keuangan dan data lainnya yang relevan dengan penelitian ini.

Data yang digunakan dalam penelitian ini berupa laporan keuangan tahunan yaitu tahun 2014, 2015, 2016, 2017 dan 2018. Laporan keuangan tahunan tersebut didapat melalui website PT Bank BRI, PT Bank Mandiri, PT Bank BNI, PT Bank BRI Syariah, PT Bank Syariah Mandiri, dan PT Bank BNI Syariah yang telah mempublikasikan laporan keuangannya. Serta data lain yang diperoleh dari berbagai literatur, seperti: buku, jurnal, dan lain sebagainya.

Variabel yang digunakan dalam penelitian ini adalah penilaian tingkat kesehatan bank dengan metode RGEC sesuai Surat Edaran Bank Indonesia Nomor 13/24/DPNP tanggal 25 Oktober 2011. Variabel serta indikator pengukurannya dirangkum dalam Tabel 1 di bawah ini.

Tabel 1. Operasionalisasi Variabel Indikator Penilaian Tingkat Kesehatan Bank

\begin{tabular}{|c|c|c|}
\hline Variabel & Indikator & Ukuran \\
\hline \multirow[t]{2}{*}{$\begin{array}{l}\text { Risk } \\
\text { Profile }\end{array}$} & $\begin{array}{l}\text { Risiko Kredit } \\
\text { Bank Umum } \\
\text { Konvensi- } \\
\text { onal }\end{array}$ & $N P L=\frac{\text { Kredit Bermasalah }}{\text { Total Kredit }} \times 100 \%$ \\
\hline & $\begin{array}{l}\text { Risiko Kredit } \\
\text { Bank Umum } \\
\text { Syariah }\end{array}$ & $N P F=\frac{\text { Pembiayaan }(K L, D, M)}{\text { Jumlah Pembiayaan }} \times 100 \%$ \\
\hline GCG & \multicolumn{2}{|c|}{$\begin{array}{l}\text { Pelaksanaan tugas dan tanggung jawab Dewan Komisaris } \\
(10 \%) \\
\text { Pelaksanaan tugas dan tanggung jawab Direksi (20\%) } \\
\text { Kelengkapan dan pelaksanaan tugas komite (10\%) } \\
\text { Penanganan benturan kepentingan (10\%) } \\
\text { Penerapan fungsi kepatuhan (5\%) } \\
\text { Penerapan fungsi audit intern (5\%) } \\
\text { Penerapan fungsi audit ekstern (5\%) } \\
\text { Penerapan manajemen risiko termasuk sistem pengendalian } \\
\text { intern ( } 7,5 \%) \\
\text { Penyediaan dana kepada pihak terkait (related party) dan } \\
\text { penyediaan dana besar (large exposures) (7,5\%) } \\
\text { Transparansi kondisi keuangan dan non keuangan bank, } \\
\text { laporan pelaksanaan GCG dan pelaporan internal (15\%) } \\
\text { Rencana strategis Bank (5\%) }\end{array}$} \\
\hline Earnings & ROA & $R O A=\frac{\text { Laba sebelum Pajak }}{\text { Rata }- \text { rata Total Aset }} \times 100 \%$ \\
\hline Capital & CAR & $\begin{array}{l}\text { CAR } \\
=\frac{\text { Mtier } 1+\text { Mtier } 2+\text { Mtier } 3-\text { Penyertc }}{\text { Aktiva Tertimbang menurut Risiko }(\text { AT }} \\
\text { Di mana: } \\
\text { Mtier 1: Modal Inti } \\
\text { Mtier 2: Modal Pelengkap } \\
\text { Mtier 3: Modal Pelengkap Tambahan }\end{array}$ \\
\hline
\end{tabular}

Sumber: Surat Edaran BI No. 9/12/DPNP 
Amelia Rahmi: Analisis Tingkat Kesehatan ...

Teknik analisis data yang digunakan dalam penelitian ini adalah analisis rasio keuangan (Financial Ratio Analysis). Analisis rasio keuangan dengan penilaian kinerja keuangan perusahaan atau bank. Analisis ini didasarkan pada data yang bersifat kuantitatif, yaitu data yang berupa angka-angka yang terdapat pada laporan keuangan perusahaan. Analisis rasio keuangan yang digunakan adalah Risk Profile, Good Corporate Governance, Earnings dan Capital.

Langkah-langkah yang dilakukan dalam analisis data adalah sebagai berikut:

Analisis rasio tingkat kesehatan bank.

Dengan menggunakan pedoman yang diberikan oleh Bank Indonesia, indikatornya dapat dilihat pada Tabel 1, dihitung skor dari masing-masing variabel yang selanjutnya dibuat peringkat sesuai peringkat yang telah disusun oleh Bank Indonesia, yaitu: Pertama, profil risiko yaitu risiko kredit dan likuiditas. Kedua, Good Corporate Governance. Ketiga, Rentabilitas (earnings). Keempat, Permodalan (capital).

\section{Uji Beda dengan Uji Mann Whitney}

Uji Mann Whitney digunakan untuk mengetahui ada tidaknya perbedaan rata-rata (means) data dua sampel yang tidak berpasangan. Uji Mann Whitney merupakan bagian dari statistik non parametrik di mana salah satu kelebihannya adalah tidak adanya syarat data harus berdistribusi normal.

\section{Pengujian Hipotesis}

Jika nilai signifikansi atau Asymp. Sig. (2-tailed) lebih kecil dari probabilitas 0,05 maka hipotesis (Ha) diterima.

Jika nilai signifikansi atau Asymp. Sig. (2-tailed) lebih besar dari probabilitas 0,05 maka hipotesis $(\mathrm{Ha})$ ditolak.

\section{HASIL PENELITIAN DAN PEMBAHASAN Risk Profile}

Tabel 2. Test Statistics NPL

\begin{tabular}{lr}
\hline & NPL atau NPF \\
\hline Mann-Whitney U & 12 \\
\hline Wilcoxon W & 132 \\
\hline$Z$ & $-4,370$ \\
\hline Asymp. Sig. (2-tailed) &, 000 \\
\hline Exact Sig. [2*(1-tailed &, $000^{\mathrm{a}}$ \\
Sig.)] & \\
\hline
\end{tabular}

a. Not corrected for ties

b. Grouping Variable: Bank Umum

Berdasarkan output SPSS di atas, diketahui nilai Asymp. Sig. (2-tailed) sebesar 0,000 lebih kecil dari probabilitas 0,05 maka hipotesis ( $\mathrm{Ha}$ ) diterima. Dengan demikian dapat disimpulkan bahwa terdapat perbedaan kinerja bank umum konvensional dengan bank umum syariah berdasarkan nilai NPL atau NPF.

Risiko kredit dalah risiko yang timbul sebagai akibat terjadinya kegagalan pihak bank dalam memenuhi kewajibannya. Terjadinya perbedaan risiko kredit antara bank umum konvensional dengan bank umum syariah dapat disebabkan oleh sistem yang digunakan berbeda. Pada bank umum konvensional, pembiayaan disebut pinjaman, sementara di bank umum syariah disebut pembiayaan.

Untuk balas jasa yang diberikan atau diterima pada bank umum konvensional berupa bunga (interest loan atau deposit) dalam persentase yang sudah ditentukan sebelumnya. Pada bank syariah, tingkat balas jasa terukur oleh sistem bagi hasil dari usaha. Selain itu, persyaratan pengajuan kredit pada perbankan syariah lebih ketat dari perbankan konvensional sehingga risiko kredit dari perbankan syariah lebih kecil dari perbankan konvensional.

Mengenai risiko usaha, bank syariah menerapkan poin "ringan sama dijinjing, berat sama dipikul" antara bank dan nasabah. Hal ini membuat semua hal yang terjadi ditanggung secara bersama-sama, baik berupa keuntungan maupun kerugian. Sementara itu pada bank konvensional biasa, pihak bank tidak berurusan 
dengan risiko yang mungkin dihadapi nasabahnya. Pihak nasabah juga tidak perlu memikirkan risiko yang mungkin terjadi kepada bank tempatnya melakukan transaksi keuangan ataupun menyimpan dana.

Perbedaan risiko yang dihadapi bank umum konvensional dengan bank umum syariah dapat dilihat juga dari data NPL dan NPF selama periode penelitian. Rata-rata NPL dari tiga bank umum konvensional selama lima tahun sebesar $78,8 \%$ sedangkan rata-rata NPF dari tiga bank umum syariah selama lima tahun sebesar $289,7 \%$.

Tabel 3. Test Statistics Good Corporate Governance

\begin{tabular}{lr}
\hline & GCG \\
\hline Mann-Whitney U & 1,5 \\
\hline Wilcoxon W & 121,5 \\
\hline Z & $-4,634$ \\
\hline Asymp. Sig. (2-tailed) &, 000 \\
\hline Exact Sig. [2*(1-tailed &, $000^{\mathrm{a}}$ \\
Sig.)] & \\
\hline
\end{tabular}

a. Not corrected for ties

b. Grouping Variable: Bank Umum

Berdasarkan output SPSS di atas, diketahui nilai Asymp. Sig. (2-tailed) sebesar 0,000 lebih kecil dari probabilitas 0,05 maka hipotesis ( $\mathrm{Ha}$ ) diterima. Dengan demikian dapat disimpulkan bahwa terdapat perbedaan kinerja bank umum konvensional dengan bank umum syariah berdasarkan nilai GCG.

Perbedaan dalam menjalankan prinsip Good Corporate Governance adalah pada segi produk dan akad baik dalam hal penghimpunan dana (funding) dan pembiayaan (lending). Dalam perbankan konvensional hanya terdapat istilah kredit dan debit saja dengan sistem bunga (interest), namun dalam perbankan syariah terdapat banyak akad seperti titipan murni, jual beli dan bagi hasil dan kerja sama, musyarokah, sewa menyewa, kebajikan dan lain sebagainya.

Hasil penelitian ini tidak sejalan dengan Penelitian Fitriana (2015) yang menunjukkan bahwa tidak terdapat perbedaan tingkat kesehatan bank BUMN syariah dan bank BUMN konvensional pada faktor GCG tahun 20122014. Tingkat kesehatan bank BUMN syariah dan bank BUMN konvensional pada faktor permodalan (capital) tahun 2012-2014 terbukti tidak ada perbedaan yang signifikan.

\section{Earnings}

Tabel 4. Test Statistics ROA

\begin{tabular}{lr}
\hline & ROA \\
\hline Mann-Whitney U & 2,5 \\
\hline Wilcoxon W & 122,5 \\
\hline Z & $-4,710$ \\
\hline Asymp. Sig. (2-tailed) &, 000 \\
\hline Exact Sig. [2*(1-tailed &, $000^{\mathrm{a}}$ \\
Sig.)] & \\
\hline
\end{tabular}

a. Not corrected for ties

b. Grouping Variable: Bank Umum

Berdasarkan output SPSS di atas, diketahui nilai Asymp. Sig. (2-tailed) sebesar 0,000 lebih kecil dari probabilitas 0,05 maka hipotesis ( $\mathrm{Ha}$ ) diterima. Dengan demikian dapat disimpulkan bahwa terdapat perbedaan kinerja bank umum konvensional dengan bank umum syariah berdasarkan nilai ROA.

Pengukuran kesehatan bank umum konvensional dan syariah dalam penelitian ini menggunakan ROA, di mana unsur yang digunakan yaitu tingkat laba dan jumlah asset. Bank umum konvensional memiliki masa pendirian yang lebih lama dibandingkan bank syariah, hal ini tentunya dapat berpengaruh pada jumlah asset yang dimiliki kedua jenis bank tersebut. Semakin lama masa pendiriannya berpotensi memiliki asset yang lebih besar. Semakin besar aset semakin besar potensi tingkat keuntungan yang dicapai bank sehingga semakin baik pula tingkat kesehatan bank pada faktor earnings dan dari segi penggunaan aset. Dengan demikian, tingkat kesehatan bank umum konvensional dengan bank umum syariah berdasarkan earnings yang diukur menggunakan ROA terdapat perbedaan. 
Amelia Rahmi: Analisis Tingkat Kesehatan ...

Untuk dapat melihat lebih jelas perbedaan ROA antara bank umum berikut ini data ROA kedua jenis bank selama konvensional dengan bank umum syariah, lima tahun.

Tabel 5. ROA Bank Umum Konvensional Periode 2014 s.d 2018

\begin{tabular}{lrrrrrr}
\hline \multirow{2}{*}{ Bank } & \multicolumn{7}{c}{ ROA } & \multicolumn{2}{c}{ Rata-rata } \\
\cline { 2 - 7 } & $\mathbf{2 0 1 4}$ & $\mathbf{2 0 1 5}$ & $\mathbf{2 0 1 6}$ & $\mathbf{2 0 1 7}$ & $\mathbf{2 0 1 8}$ & \\
\hline BRI & 4,73 & 4,19 & 3,84 & 3,69 & 3,68 & 4,03 \\
\hline Mandiri & 3,57 & 3,15 & 1,95 & 2,72 & 3,17 & 2,91 \\
\hline BNI & 3,5 & 2,6 & 2,7 & 2,7 & 2,8 & 2,86 \\
\hline & \multicolumn{7}{c}{ Rata-rata } & & & $\mathbf{3 , 2 7}$ \\
\hline
\end{tabular}

Tabel 6. ROA Bank Syariah Periode 2014 s.d 2018

\begin{tabular}{|c|c|c|c|c|c|c|}
\hline \multirow[t]{2}{*}{ Bank } & \multicolumn{5}{|c|}{ ROA } & \multirow[t]{2}{*}{ Rata-rata } \\
\hline & 2014 & 2015 & 2016 & 2017 & 2018 & \\
\hline BRI Syariah & 0,08 & 0,77 & 0,95 & 0,51 & 0,43 & 0,55 \\
\hline $\begin{array}{l}\text { Mandiri } \\
\text { Syariah }\end{array}$ & $-0,04$ & 0,56 & 0,59 & 0,59 & 0,88 & 0,52 \\
\hline BNI Syariah & 1,27 & 1,43 & 1,44 & 1,31 & 1,42 & 1,37 \\
\hline \multicolumn{6}{|c|}{ Rata-rata } & 0,81 \\
\hline
\end{tabular}

\section{Capital}

Tabel 6. Test Statistics Capital

\begin{tabular}{lr}
\hline & CAR \\
\hline Mann-Whitney U & 59 \\
\hline Wilcoxon W & 179 \\
\hline Z & $-2,238$ \\
\hline Asymp. Sig. (2-tailed) &, 025 \\
\hline Exact Sig. [2*(1-tailed &, $026^{\mathrm{a}}$ \\
Sig.)]
\end{tabular}

a. Not corrected for ties

b. Grouping Variable: Bank Umum

Berdasarkan output SPSS di atas, diketahui nilai Asymp. Sig. (2-tailed) sebesar 0,025 lebih kecil dari probabilitas 0,05 maka hipotesis ( $\mathrm{Ha}$ ) diterima. Dengan demikian dapat disimpulkan bahwa terdapat perbedaan kinerja bank umum konvensional dengan bank umum syariah berdasarkan nilai CAR.

CAR adalah rasio yang memperlihatkan seberapa jauh seluruh aktiva bank yang mengandung risiko (kredit, penyertaan, surat berharga, tagihan pada bank lain) ikut dibiayai dari dana modal sendiri bank di samping memperoleh dana-dana dari sumber-sumber di luar bank, seperti dana masyarakat, pinjaman (utang), dan lain-lain. Dengan kata lain, Capital Adequacy Ratio adalah rasio kinerja bank untuk mengukur kecukupan modal yang dimiliki bank untuk menunjang aktiva yang mengandung atau menghasilkan risiko, misalnya kredit yang diberikan. CAR merupakan indikator terhadap kemampuan bank untuk menutupi penurunan aktivanya sebagai akibat dari kerugiankerugian bank yang disebabkan oleh aktiva yang berisiko (Dendawijaya, 2009). Berdasarkan pengertian tersebut jelas terlihat bahwa CAR salah satunya mengandung unsur kredit. Sistem bank umum konvensional dengan syariah dalam hal kredit memiliki perbedaan, sebagaimana hasil pengujian sebelumnya bahwa kinerja bank umum konvensional dengan bank umum syariah dari sudut pandang risiko kredit terdapat perbedaan. Hal ini tentu berimbas juga pada CAR, sehingga CAR kinerja bank umum konvensional dengan bank umum syariah memiliki perbedaan.

Hasil penelitian ini tidak sesuai dengan hasil penelitian Fitriana (2015) yang menunjukan tidak adanya perbedaan tingkat kesehatan bank ini disebabkan kemampuan 
bank dalam menyediakan modal minimum yang telah di tetapkan oleh bank Indonesia kepada seluruh bank BUMN baik syariah maupun konvensional.

\section{PENUTUP}

Berdasarkan hasil analisis data dengan menggunakan Uji Mann Whitney dapat diambil kesimpulan. Pertama, antara NPL bank umum konvensional dengan NPF bank umum Syariah pada periode 2014 sampai 2018 terdapat perbedaan. Artinya tingkat kesehatan bank umum konvensional dengan bank umum syariah berdasarkan risk profile terdapat perbedaan. Hal tersebut dapat dilihat dari nilai Asymp. Sig. (2-tailed) sebesar 0,000 lebih kecil dari probabilitas 0,05 maka hipotesis satu (H1) diterima. Kedua, GCG antara bank umum konvensional dengan bank umum syariah pada periode 2014 sampai 2018 terdapat perbedaan. Artinya tingkat kesehatan bank umum konvensional dengan bank umum syariah berdasarkan GCG terdapat perbedaan. Hal tersebut dapat dilihat dari nilai Asymp. Sig. (2-tailed) sebesar 0,000 lebih kecil dari probabilitas 0,05 maka hipotesis dua $(\mathrm{H} 2)$ diterima. Ketiga, ROA antara bank umum konvensional dengan bank umum syariah pada periode 2014 sampai 2018 terdapat perbedaan. Artinya tingkat kesehatan bank umum konvensional dengan bank umum syariah berdasarkan earnings terdapat perbedaan. Hal tersebut dapat dilihat dari nilai Asymp. Sig. (2-tailed) sebesar 0,000 lebih kecil dari probabilitas 0,05 maka hipotesis tiga (H3) diterima. Keempat, CAR antara bank umum konvensional dengan bank umum syariah pada periode 2014 sampai 2018 terdapat perbedaan. Artinya tingkat kesehatan bank umum konvensional dengan bank umum syariah berdasarkan capital terdapat perbedaan. Hal tersebut dapat dilihat dari nilai Asymp. Sig. (2-tailed) sebesar 0,025 lebih kecil dari probabilitas 0,05 maka hipotesis empat (H4) diterima.
Berdasarkan hasil analisis dan penelaahan serta keterbatasan penelitian ini, maka dapat disarankan hal-hal sebagai berikut. Pertama, penelitian selanjutnya disarankan untuk menambah jumlah bank umum baik konvensional maupun bank syariah. Kedua, penelitian selanjutnya disarankan untuk menambah periode pengamatan dengan harapan dapat memberikan hasil penelitian yang lebih baik. Ketiga, penelitian selanjutnya disarankan untuk memasukkan tujuh indikator lainnya dalam mengukur risiko, yaitu risiko pasar, risiko likuiditas, risiko operasional, risiko hokum, risiko stratejik, risiko kepatuhan dan risiko reputasi. Keempat, penelitian selanjutnya disarankan untuk menambah ukuran earnings lainnya seperti Net Profit Margin dan Return on Equity.

\section{REFERENSI}

Bank Indonesia. (2011). Peraturan Bank Indonesia Nomor 13/1/PBI/2011 Tentang Penilaan Tingkat Kesehatan Bank Umum. Tersedia di www.ojk.go.id [diakses tanggal 5 Februari 2019]. (2011). Surat Edaran No. 13/24/DPNP Tentang Penilaian Tingkat Kesehatan Bank Umum. Tersedia di www.ojk.go.id [diakses tanggal 5 Februari 2019].

Dzulkirom, M dan Saifi, M. (2015). Analisis Kinerja Keuangan Bank Konvensional dan Bank Syariah dengan Menggunakan Pendekatan RGEC (Studi pada PT. BRI, Tbk dan PT.BRI Syariah Periode 2011-2013. Jurnal Administrasi Bisnis (JAB), Vol 27 No 1 Oktober 2015. Hal 1-6

Fitriana, N., dkk. (2015). Tingkat Kesehatan Bank BUMN Syariah dengan Bank BUMN Konvensional: Metode RGEC (Risk Profile, Good Corporate Governance, Earning dan Capital). Jurnal Ekonomi dan Bisnis, Volume 17 Nomor: 02 September 2015 Hal 1-12, ISSN: 1663-0908.

Jumingan. (2011). Analisis Laporan Keuangan. Jakarta: PT Bumi Aksara. 
Amelia Rahmi: Analisis Tingkat Kesehatan ...

Kasmir. (2015). Dasar-Dasar Perbankan. Edisi Revisi 2014. Jakarta: PT Rajawali Pers.

Rahman, A Tessa. dkk. (2016). Analisis Kinerja Perbankan dengan Pendekatan RGEC (Risk Profile, Good Corporate Governance, Earning, and Capital) untuk Mengetahui Tingkat Kesehatan Bank (Studi pada Bank BUMN dan Bank Pembangunan Daerah Periode 2012 -2014). Jurnal Administrasi Bisnis (JAB), Vol 35 No 1 Juni 2016, Hal 96103.

Saifi, M dan Zahroh, Z. (2016). Penerapan Pendekatan RGEC (Risk Profile, Good
Corporate Governance, Earning dan Capiytal) dalam Menganalisis Kinerja Bank untuk Mengetahui Tingkat Kesehatan Bank (Studi Kasus PT Bank Tabungan Negara (Persero) Tbk. Periode 2013-2015). Jurnal Administrasi Bisnis (JAB), Vol 37 No. 1 2016, Hal 28-36.

Siregar, S. (2010). Statistika Deskriptif untuk Penelitian. Jakarta: Rajawali Pers

Sugiono. (2012). Metode Penelitian Kuantitatitf Kualitatif dan R\&D. Bandung: Alfabeta

www.idx.com 